\title{
Erratum: delli Paoli et al. (2020)
}

In the article delli Paoli, G., van de Laarschot, D., Friesema, E.H., Verkaik, R., Giacco, A., Senese, R., Arp, P. P., Jhamai, P., Pagnotta, S. M., Broer, L., Uitterlinden, A. G., Lanni, A., Zillikens, M., \& de Lange, P. (2020) Short-term, combined fasting and exercise improves body composition in healthy males; International Journal of Sport Nutrition and Exercise Metabolism, 30(6),
386-395; https://doi.org/10.1123/ijsnem.2020-0058, the copyright was assigned to Human Kinetics, Inc. The authors subsequently obtained Open Access distributed under the terms of the Creative Commons Attribution License CC BY 4.0, which reverted copyright back to the authors. The online version of this article has been corrected. 